\title{
THE DEFICIENCY OF 21-HYDROXYLASE AS A PARADIGM OF SEGREGATION ANALYSIS ${ }^{1}$
}

\author{
Norikazu YASUDA ${ }^{2}$ and Nobuchika SAITO ${ }^{3}$ \\ ${ }^{2}$ Division of Genetics, National Institute of Radiological \\ Sciences, Chiba 260, Japan \\ ${ }^{3}$ Department of Pediatrics, Tokyo Medical and Dental \\ University, Tokyo 311, Japan
}

\begin{abstract}
Summary Eleven families of 21-hydroxylase deficiency are submitted to segregation analysis. With demonstration of the computational procedure, it is confirmed that the mode of inheritance of this disease is autosomal recessive with no sporadic case in the present material.
\end{abstract}

\section{INTRODUCTION}

Much efforts on the segregation frequency of rare disease under single ascertainment have been done by various authors (Weinberg, 1912; Haldane, 1932; Fisher, 1934; Bailey, 1951; Smith, 1956; Li, 1964; Sevin, 1975 and Davie, 1979), but statistical studies have apparently been overlooked on genetic heterogeneity. Haldane (1949) first introduced a concept of the sporadic cases in the segregation analysis which has been developed by Morton (1959). Although Crow (1965) has illustrated the computational procedures, yet it is heavily dependent upon electronic computers.

In the present communication, simple formulae for a test of genetic heterogeneity as well as an estimation of the proportion of sporadic cases, and the test of segregation frequency are given for data collected by single ascertainment, a common practice of family selection on rare diseases. The formulae are then applied to a typical example, the deficiency of 21-hydroxylase that is the most common type of congenital adrenal hyperplasia (childs et al., 1956)

\section{SEGREGATION ANALYSIS}

In single ascertainment where a nuclear family is selected through an affected child (proband), the families apart from the probands could be treated as a random

Received May 2, 1980

${ }^{1}$ Supported in part by a grant from the Ministry of Health and Wealfare, Japan 
sample from population; namely, the method of family selection becomes a complete ascertainment through parent. Because of removing probands from the sample, the probability of ascertainment becomes zero.

Suppose that $\mathrm{p}$ and $\mathrm{x}$ be respectively the segregation frequency and the proportion of sporadic cases. For the sibship size $s$ with the number of affected siblings $r$, including proband, the expected probability of simplex families where there only one affected person or proband in sibling is

$$
P(r=1)=x+(1-x)(1-p)^{s-1}
$$

since simplex families are either due to sporadic cases or due to chance isolated cases under genetic hypothesis. The expected probability of multiplex families, having at least two affected individuals in sibling is

$$
P(r)=(1-x)_{s-1} C_{x-1} p^{r-1}(1-p)^{s-r} \quad(r=2,3, \ldots, s)
$$

where ${ }_{s-1} C_{r-1}=(s-1) ! /[(r-1) !(s-r) !]$ is the binomial coefficient (Morton, 1959).

A method of maximum likelihood scoring under the genetic hypothesis of no sporadic case $(x=0)$ yields the U-scores which represent the observed deviation from the genetic hypothesis as

$$
U_{P}=\frac{(R-N)-(T-N) p}{p(1-p)}
$$

where $R, N$ and $T$ are the total number of affected siblings, number of siblings with only one proband and total number of siblings, respectively, and

$$
\mathrm{U}_{\mathrm{x}}=\sum_{\mathrm{s}} \frac{\mathbf{n}_{\mathrm{s} 1}}{(1-\mathrm{p})^{\mathrm{s}-1}}-\mathrm{N}
$$

in which $\mathrm{n}_{\mathrm{s} 1}$ is the number of simplex family with sibship size s. The amount of informations, designated by $\mathrm{K}$ subscripted with the corresponding parameters, are then

$$
\begin{aligned}
& K_{p p}=\frac{T-N}{p(1-p)} \\
& K_{p x}=K_{x p}=-K_{p p}
\end{aligned}
$$

and

$$
\mathrm{K}_{\mathrm{xx}}=\sum_{\mathrm{s}} \frac{\mathrm{n}_{\mathrm{s}}}{(1-\mathrm{p})^{\mathrm{s}-1}}-\mathrm{N}
$$

where $n_{s}$ is the observed number of family with the sibship size s. 
A test of genetic hypothesis for the segregation frequency may be performed by the value

$$
\chi^{2}=\frac{U_{p}^{2}}{K_{p p}}=(T-N) \cdot \frac{(\hat{p}-p)^{2}}{p(1-p)}
$$

which asymptotically be the chi-square variate with one degree of freedom. The observed segregation frequency $\hat{p}$ is obtainable as a solution of the maximum likelihood equation $\mathrm{U}_{\mathrm{p}}=0$; namely,

$$
\hat{\mathrm{p}}=\frac{\mathrm{R}-\mathrm{N}}{\mathrm{T}-\mathrm{N}}
$$

with the variance

$$
V(\hat{\mathrm{p}})=\mathrm{K}_{\hat{\mathrm{p}} \hat{\mathrm{p}}}^{-1}=\frac{(\mathrm{R}-\mathrm{N})(\mathrm{T}-\mathrm{R})}{(\mathrm{T}-\mathrm{N})^{3}}
$$

The results of (9) and (10) were first derived by Fisher (1934).

The test of the hypothesis of no sporadic case $(x=0)$ may be made by utilizing the value of asymptotic chi-square with one degree of freedom:

$$
\chi^{2}=\mathrm{U}_{\mathrm{x}}{ }^{2} / \mathrm{K}_{\mathrm{xx}}
$$

An approximate estimate and the standard error of the proportion of sporadic cases may be computed from

$$
\hat{x}=U_{x} / K_{x x} \pm \sqrt{1 / K_{x x}} .
$$

\section{RESULTS}

Based on eleven probands of the deficiency of 21-hydroxylase, their siblings as well as parents are examined by the endocrinological assay and the HLA typing (Nishimura et al., 1980). Thus the method of ascertainment is typically single for eleven nuclear families. Since all parents are phenotypically normal, a SR table was constructed as shown in Table 1 , in which each entry, denoted by $\mathrm{n}_{\mathrm{sr}}$, is the observed number of families with the sibship size $s$ and the number of affected siblings $r$. As noticed in (1) and (2), one child family $(s=1)$ or uniplex family does not give any information on disease segregation, $N=10$ families contribute to the analysis. The total number of affected persons was $R=14$, and the number of siblings was $T=25$ (Table 2). The observed frequency of segregation is therefore $\hat{p}=0.27 \pm 0.11$ (formula (9)) which indicates an autosomal recessive gene to be responsible. Under the genetic hypothesis that $\mathrm{p}=1 / 4$ and $\mathrm{x}=0$, the $\mathrm{U}$ and $\mathrm{K}$ scores are (from (3), (4), (5) and (7)) $\mathrm{U}_{\mathrm{p}}=1.3333, \mathrm{~K}_{\mathrm{pp}}=80$., $\mathrm{U}_{\mathrm{x}}=-0.2224$, and $\mathrm{K}_{\mathrm{xx}}=$ 5.7033. The value of chi-square for $\mathrm{p}$ and $\mathrm{x}$ are respectively $(1.3333)^{2} / 80 .=0.0222$ 
Table 1. The distribution of the 21-hydroxylase deficiency among sibships born to normal parents (SR table).

\begin{tabular}{|c|c|c|c|c|c|}
\hline s) & 1 & 2 & 3 & 4 & $\mathrm{n}_{\mathrm{s}}$ \\
\hline 1 & 1 & & & & 1 \\
\hline 2 & 6 & 0 & & & 6 \\
\hline 3 & 1 & $I$ & $I$ & & 3 \\
\hline 4 & 0 & 1 & 0 & 0 & $I$ \\
\hline & 8 & 2 & 1 & 0 & 11 \\
\hline
\end{tabular}

$\mathrm{s}=$ size of sibships; $\mathrm{r}=$ number of affected in sibships; $\mathrm{n}_{5}=$ number of sibships with the size $\mathrm{s}$.

Table 2. Segregation analysis of the 21-hydroxylase deficiency (Single ascertainment).

\begin{tabular}{ccccccc}
\hline $\mathrm{s}$ & $\mathrm{n}_{\mathrm{s} 1}$ & $\mathrm{n}_{\mathrm{s}}$ & $\sum_{\mathrm{r}=1}^{\mathrm{s}} \mathrm{r} \cdot \mathrm{n}_{\mathrm{sr}}$ & $\frac{\mathrm{n}_{\mathrm{s} 1}}{(1-1 / 4) \mathrm{s}-1}$ & $\frac{\mathrm{n}_{\mathrm{s}}}{(1-1 / 4) \mathrm{s}-1}$ & $\mathrm{~s} \cdot \mathrm{n}_{\mathrm{s}}$ \\
\hline 2 & 6 & 6 & 6 & $6 \times 1.3333$ & $6 \times 1.3333$ & 12 \\
3 & 1 & 3 & 6 & $1 \times 1.7777$ & $3 \times 1.7777$ & 9 \\
4 & 0 & 1 & 2 & $0 \times 2.3704$ & $1 \times 2.3704$ & 4 \\
\hline sum & & $\mathrm{N}=10$ & $\mathrm{R}=14$ & 9.7776 & 15.7033 & $\mathrm{~T}=25$ \\
\hline
\end{tabular}

$\mathrm{U}_{\mathfrak{p}}=\frac{14-10-0.25(25-10)}{0.25(1-0.25)}=1.3333$

$\mathrm{K}_{\mathrm{pp}}=\frac{25-10}{0.25(1-0.25)}=80 . \quad\left(=-\mathrm{K}_{\mathrm{px}}\right)$

$\mathrm{U}_{\mathrm{x}}=9.7776-10=-0.2224$

$\mathrm{K}_{\mathrm{xx}}=15.7033-10=5.7033$.

(from (8)) and $(-0.2224)^{2} / 5.7033=0.0087$ (from (11)). Two values are not statistically significant at 5 percent level. Those calculations do not themselves prove that the deficiency of 21-hydroxylase is due to a recessive gene without genetic heterogeneity, but do infer that the distribution of affected children in the families does not differ significantly from that would be expected if the disease were due to such a gene.

An approximate estimate of the proportion of sporadic cases is from (12) as $\mathrm{x}=-0.04 \pm 0.42$. Table 3 depicts the goodness of fit test of the data to the genetic 
Table 3. A test of goodness of fit of the distribution of 21-hydroxylase deficiency to the hypothesis of an autosomal recessive inheritance without genetic heterogeneity $\left(\mathrm{H}_{0}: \mathrm{p}=0.25\right.$ and $\left.\mathrm{x}=0\right)$.

\begin{tabular}{ccccc}
\hline $\mathrm{s}$ & $\mathrm{r}$ & Observed number & Expected number & Chi-square value \\
\hline 1 & 1 & 1 & 1 & 0 \\
2 & 1 & 6 & 4.50 & 0.50 \\
2 & 2 & 0 & 1.50 & 1.50 \\
3 & 1 & 1 & 1.69 & 0.28 \\
3 & 2 & 1 & 1.12 & 0.01 \\
3 & 3 & 1 & 0.19 & 3.45 \\
4 & 1 & 0 & 0.42 & 0.42 \\
4 & 2 & 1 & 0.42 & 0.80 \\
4 & 3 & 0 & 0.14 & 0.14 \\
4 & 4 & 0 & 0.02 & 0.02 \\
\hline Total & & 11 & 11.00 & 7.12 \\
\hline
\end{tabular}

hypothesis that $H_{0}: p=1 / 4$ and $x=0$. The result is by no means statistically significant $\left(\chi^{2}=7,12\right.$ with four degrees of freedom).

\section{DISCUSSION}

A negative estimate of $x$ may reflect the sampling bias toward to multiplex family. This tendency of family selection could also be noticed in the observed frequency of segregation $(\hat{p}=0.27)$, somewhat exceeded the expected one $(p=0.25)$. By all means, the excess is negligible.

A high value of the standard error to $x$ indicates either due to a smallness of sample size or due to possible genetic heterogeneity. However, HLA typing revealed that not only the locus of 21-hydroxylase deficiency was tightly linked with the HLA loci so that a gene controlling the deficiency of 21-hydroxylase was on no. 6 chromosome, but also all parents were carriers of the gene responsible for the deficiency of 21-hydroxylase (Nishimura et al., loc. cit.). This means that there is no sporadic case of the disease in the present data. Segregation analysis might have required a large size of sample to reduce the standard error of $x$ to prove factually no sporadic case. In addition, it can be shown that the estimate of the proportion of sporadic case is very sensitive to the probability of ascertainment, yielding the highest value at single selection (Yasuda, 1981). In the present paradigm therefore there is little evidence of existance of sporadics. Statistical analysis thus should accompany with laboratory approaches, or at least should indicate the direction of laboratory studies. In summary, we conclude that in the present material the deficiency of 21-hydroxylase is controlled by an autosomal recessive gene. 
Acknowledgements The authors wish to thank Professor Takehiko Sasazuki, Department of Human Genetics, Tokyo Medical and Dental University, for his suggestions and the access of the present study.

\section{REFERENCES}

Bailey, N.T.J. 1951. The estimation of the frequencies of recessives with incomplete multiple selection. Ann. Eugen. 16: 223-225.

Childs, B., Grumbach, M.N. and Van Wyk, J.J. 1956. Virilizing adrenal hyperplasia: a genetic and hormonary study. J. Clin. Invest. 35: 213-222.

Crow, J.F. 1965. Problems of ascertainment in the analysis of family data. In Genetics and Epidemiology of Chronic diseases. (eds. J.V. Neel, M.W. Shaw and W.J. Schull). US Dept. Health, Education and Welfare, Washington. pp. 23-44.

Davie, A.M. 1979. The 'single' method for segregation analysis under incomplete ascertainment. Ann. Hum. Genet. 42: 507-512.

Fisher, R.A. 1934. The effect of methods of ascertainment upon the estimation of frequencies. Ann. Eugen. 6: 13-25.

Haldane, J.B.S. 1932. A method for investigating recessive characters in man. J. Genet. 28: 251255.

Haldane, J.B.S. 1949. A test for homogeneity of records of familial abnormalities. Ann. Eugen. 14: $339-341$.

Li, C.C. 1964. Estimation of recessive proportion by first appearance time. Ann. Hum. Genet. 28: $177-180$.

Morton, N.E. 1959. Genetic tests under incomplete ascertainment. Am. J. Hum. Genet. 11: 1-16.

Nishimura, Y., Sasazuki, T. and Saito, N. 1980. Close genenetic linkage between HLA and Congenital adrenal hyperplasia in Japanese population. (In preparation).

Sevin, S. 1975. Testing the Mendelian segregation ratio under incomplete ascertainment. Hum. Hered. 25: 194-203.

Smith, C.A.B. 1956. A test for segregation ratios in family data. Ann. Hum. Genet. 20: 257-265.

Yasuda, N. 1981. A statistical analysis of the genetic heterogeneity of diseases. Jpn. J. Human Genet. 26 (1): (in press).

Weinberg, W. 1912. Methoden und Fehlerquellen der Untersuchung auf Mendelsche Zahlen beim Menschen. Arch. Rassenbiol. 9: 165-174. 